\title{
SGLT2 inhibitors and lower limb complications: the diuretic-induced hypovolemia hypothesis
}

\author{
Louis Potier ${ }^{1,2,6^{*}}$ (D), Kamel Mohammedi ${ }^{3,4,5}$, Gilberto Velho ${ }^{1}$ and Ronan Roussel ${ }^{1,2}$
}

\begin{abstract}
In a recent meta-analysis of randomized controlled trials of sodium glucose co-transporter 2 inhibitors (SGLT2i) in patients with diabetes, Lin and colleagues showed a positive association between SGLT2i-induced blood pressure and weight reduction and the risk of lower limb events. These results support the potential mechanism of a volume depletion effect of SGLT2i to explain the increase risk of amputation observed with this pharmacological class. Since the first result of the CANVAS trial raised a concern regarding the risk of amputation with SGLT2i, this hypothesis emerged from studies showing a higher incidence of amputations in patients with diabetes using diuretics. Furthermore, recent data found that copeptin, a surrogate marker of hydration status was also associated with lower limb outcomes. In conclusion, this assumption of diuretic-induced hypovolemia explanation highlights the fact that medications that induce a contraction of plasma volume, both traditional and novel agents with a diuretic mode of action should be introduced cautiously in patients with diabetes at high risk of diabetic foot events.
\end{abstract}

Keywords: SGLT2 inhibitors, lower limb events, amputations, diuretics, hypovolemia

We read with great interest the Original Investigation by Lin and colleagues who performed an updated metaanalysis of randomized controlled trials of sodium glucose co-transporter 2 inhibitors (SGLT2i) in patients with diabetes [1]. The authors assessed associations between SGLT2i use and risk of lower-limb outcomes including lower-limb amputation (LLA), peripheral arterial disease (PAD) and diabetic foot events (DFE).

The results of the CANVAS trial showing excess risk of LLA in the canagliflozin arm versus placebo, raised significant concerns on the use of this new class of glucose lowering drugs in clinical practice [2]. This is particularly true in subjects suffering from previous or ongoing diabetic foot ulcers and/or PAD who show the highest

\footnotetext{
*Correspondence: louis.potier@gmail.com

${ }^{6}$ Service d'Endocrinologie Diabétologie Nutrition, Groupe Hospitalier Bichat - Claude Bernard, 46 rue Henri Huchard, 75877 Paris Cedex 18, France

Full list of author information is available at the end of the article
}

risk of LLA. A large body of data was published on the subject, including observational, meta-analysis, pharmacovigilance and randomized studies [3]. All these studies have failed so far to elucidate the problem in a definitive way. However, in line with the results of Lin et al., the risk of LLA does not appear to be a class effect but rather related specifically to canagliflozin.

One of the most interesting and original aspect of this meta-analysis is the data regarding the association between blood pressure and weight reduction and the risk of lower-limb outcomes. The authors showed that greater weight and blood pressure (both systolic and diastolic) reduction induced by SGLT2i, were associated with higher risk of LLA, PAD and DFE. As extensively discussed by the authors, these results suggest that SGLT2i, through their diuretic effect, could induce volume depletion along with decreased tissue perfusion which then led to tissue necrosis and LLA. To support this diuresis-driven hypothesis, they mentioned 
the study by Erkens et al. showing that the use of thiazide diuretics increased the risk of LLA in population of subjects with type 2 diabetes [4]. We would like to bring to the attention of the authors and the readers some other data supporting this potential explanatory mechanism. First, two randomized controlled trials, the large Antihypertensive and Lipid Lowering Treatment to Prevent Heart Attack (ALLHAT) and the Intervention as a Goal in Hypertension Treatment (INSIGHT) trials showed a trend towards a higher rate of PADrelated events with chlorthalidone and co-amilozide respectively compared to non-diuretic blood pressure lowering treatments [5, 6]. In 2015, Gary et al. reported in cross-sectional observational study of 1000 participants with known PAD, a 1.5-fold increased risk of critical limb ischemia with use of loop diuretics [7]. More recently, we assessed this volume depletion hypothesis in a study comparing the risk of LLA according to the use of diuretics in patients with diabetes. Among 1459 patients with type 2 diabetes, we found a significant increased risk of lower-limb events (including LLA and lower-limb revascularization) in participants who were on diuretics (adjusted hazard ratio 1.49 [95 \% CI, 1.01, 2.19; $\mathrm{p}=0.04]$ ) [8]. Thereafter, in the light of our previous study, we assessed the relationship between copeptin, a surrogate of vasopressin and therefore hydration status, and LLA in people with diabetes. We reported in cohorts of type 1 and type 2 diabetes that baseline plasma copeptin was significantly associated with LLA (adjusted HR $1.89(1.28-2.82), \mathrm{p}=0.002$ in type 1 diabetes and $1.42(1.15-1.74), \mathrm{p}=0.001$ in type 2 diabetes) [9]. Furthermore, our data were supported by a publication of Alshnbari et al. showing a 2.3-fold higher risk of LLA in diuretic-treated patients in a retrospective cohort study of 10,320 type 2 diabetes patients within the UK population (adjusted HR: 2.45; 95 \%CI: $1.63-$ 3.69). This association remained significant in the propensity score matched cohort [10].

To conclude, the study by Lin et al. added some new and interesting data to support the hypothesis raised by us and others that the risk of LLA associated with the use SGLT2i could be mediated by the diuretic-induced hypovolemia, which would worsen hypoperfusion of distal lower-extremities, triggering ischemia and necrosis, eventually leading to amputation. Even if recent studies from registries or randomized controlled trials provided reassuring data on the safety of SGLT2i, physicians should be aware of this potential mechanism and pay close attention to the diabetic foot events risk especially at the initiation phase where the volume depletion effect is more evident.

\section{Abbreviations}

SGLT2i: Sodium glucose co-transporter 2 inhibitors; LLA: Lower-limb amputation; PAD: Peripheral arterial disease; DFE: Diabetic foot events.; CANVAS:

CANagliflozin CardioVascular Assessment Study..

\section{Acknowledgements \\ None.}

\section{Authors' contributions}

Drafting of the manuscript: all authors. Critical revision of the manuscript for important intellectual content and final approval of the version to be published: All authors. All authors read and approved the final manuscript.

\section{Funding}

This work was not supported by any funding.

Availability of data and materials

Not applicable.

\section{Declarations}

Ethics approval and consent to participate

Not applicable.

\section{Consent for publication}

Not applicable.

\section{Competing interests}

LP reports grants, personal fees and non-financial support from NOVO NORDISK, grants, personal fees and non-financial support from SANOFI, personal fees and non-financial support from ELI LILLY, non-financial support from SERVIER, outside the submitted work and all modest. RR reports grants, personal fees and non-financial support from sanofi, personal fees and non-financial support from MSD, grants from Amgen, personal fees from Physiogenex, personal fees from Astra-Zeneca, grants and personal fees from Novo Nordisk, personal fees from Janssen, personal fees from Eli Lilly, personal fees from Abbott, personal fees from Medtronic, personal fees from Servier, outside the submitted work and all modest. KM reports personal fees and non-financial support from Novo Nordisk and Sanofi and non-financial support from VitalAir. GV have nothing to disclose.

\section{Author details}

${ }^{1}$ Centre de Recherche des Cordeliers, INSERM, Université de Paris, Sorbonne Université, Paris, France. ${ }^{2}$ Hôpital Bichat, Assistance Publique Hôpitaux de Paris, Paris, France. ${ }^{3}$ Department of Endocrinology, Diabetes and Nutrition, Bordeaux University Hospital, Hôpital Haut-Lévêque, Pessac, France. ${ }^{4}$ Faculty of Medicine, University of Bordeaux, Bordeaux, France. ${ }^{5}$ INSERM unit 1034, Biology of Cardiovascular Diseases, Pessac, France. ${ }^{6}$ Service d'Endocrinologie Diabétologie Nutrition, Groupe Hospitalier Bichat - Claude Bernard, 46 rue Henri Huchard, 75877 Paris Cedex 18, France.

Received: 5 May 2021 Accepted: 8 May 2021

Published online: 13 May 2021

\section{References}

1. Lin C, Zhu X, Cai X, Yang W, Lv F, Nie L, et al. SGLT2 inhibitors and lower limb complications: an updated meta-analysis. Cardiovasc Diabetol. 2021;20:91

2. Neal B, Perkovic V, Mahaffey KW, de Zeeuw D, Fulcher G, Erondu N, et al. Canagliflozin and cardiovascular and renal events in type 2 diabetes. N Engl J Med. 2017;377:644-57.

3. Vlachopoulos C, Terentes-Printzios D, Tsioufis K. Do SGLT2 inhibitors increase the risk of amputation? Make haste slowly. Eur Heart J. 2020;42(18):1739-41.

4. Erkens JA, Klungel OH, Stolk RP, Spoelstra JA, Grobbee DE, Leufkens HGM. Antihypertensive drug therapy and the risk of lower extremity 
amputations in pharmacologically treated type 2 diabetes patients. Pharmacoepidemiol Drug Saf. 2004;13:139-46.

5. ALLHAT Officers and Coordinators for the ALLHAT Collaborative Research Group. The Antihypertensive and Lipid-Lowering Treatment to Prevent Heart Attack Trial. Major outcomes in high-risk hypertensive patients randomized to angiotensin-converting enzyme inhibitor or calcium channel blocker vs diuretic: The Antihypertensive and Lipid-Lowering Treatment to Prevent Heart Attack Trial (ALLHAT). JAMA. 2002;288:2981-97.

6. Brown MJ, Palmer CR, Castaigne A, de Leeuw PW, Mancia G, Rosenthal T, et al. Morbidity and mortality in patients randomised to double-blind treatment with a long-acting calcium-channel blocker or diuretic in the International Nifedipine GITS study: Intervention as a Goal in Hypertension Treatment (INSIGHT). Lancet Lond Engl. 2000;356:366-72.

7. Gary T, Belaj K, Hafner F, Eller P, Rief P, Hackl G, et al. Graz critical limb ischemia score: a risk score for critical limb ischemia in peripheral arterial occlusive disease. Medicine. 2015;94:e1054.
8. Potier L, Roussel R, Velho G, Saulnier P-J, Bumbu A, Matar O, et al. Lower limb events in individuals with type 2 diabetes: evidence for an increased risk associated with diuretic use. Diabetologia. 2019;62:939-47.

9. Potier L, Roussel R, Marre M, Bjornstad P, Cherney DZ, El Boustany R, et al. Plasma copeptin and risk of lower-extremity amputation in type 1 and type 2 diabetes. Diabetes Care. 2019:42:2290-7.

10. Alshnbari A, Alkharaiji M, Anyanwagu U, Idris I. Diuretics and risk of lower extremity amputation amongst patients with insulin-treated type 2 diabetes - exploring the mechanism of possible sodium glucose cotransporter 2 inhibitor induced risk of lower extremity amputations. Curr Med Res Opin. 2020;36:1985-9.

\section{Publisher's Note}

Springer Nature remains neutral with regard to jurisdictional claims in published maps and institutional affiliations.
Ready to submit your research? Choose BMC and benefit from:

- fast, convenient online submission

- thorough peer review by experienced researchers in your field

- rapid publication on acceptance

- support for research data, including large and complex data types

- gold Open Access which fosters wider collaboration and increased citations

- maximum visibility for your research: over $100 \mathrm{M}$ website views per year

At BMC, research is always in progress.

Learn more biomedcentral.com/submissions 